\title{
Parents' use of mobile applications in the first year of parenthood: a narrative review of the literature
}

\author{
Anila Virani, Linda Duffett-Leger, Nicole Letourneau \\ Faculty of Nursing, University of Calgary, Calgary, Canada \\ Contributions: (I) Conception and design: All authors; (II) Administrative support: All authors; (III) Provision of study materials or patients: All \\ authors; (IV) Collection and assembly of data: A Virani; (V) Data analysis and interpretation: A Virani, L Duffett-Leger; (VI) Manuscript writing: All \\ authors; (VII) Final approval of manuscript: All authors. \\ Correspondence to: Dr. Anila Virani, RN, BScN, MN, PhD. Faculty of Nursing, University of Calgary, 2500 University Drive NW, Calgary, Alberta, \\ T2N 1N4, Canada. Email: avirani@ucalgary.ca.
}

\begin{abstract}
Parent's use of apps to support their parenting is on the rise. The purpose of this narrative review of the literature is to explore the characteristics of research on parents' app use in the first year of parenthood, types of apps available to parents, and the factors that encourage or discourage parents' app use. A narrative review of the literature and thematic analysis of the full-text English language articles between January 2000 and December 2019 relating to parents' use of apps in the first year of parenthood was conducted to provide a comprehensive overview of the existing literature using seven academic databases: CINAHL Plus with Full Text, MEDLINE, SocINDEX with Full Text, PsychINFO, Academic Search Complete, Web of Science, and Google Scholar. Forty-one articles were included based on prespecified eligibility criteria. The majority $(n=30)$ discussed a parenting app or mHealth intervention that included an app. Most studies $(n=15)$ recruited women as participants and were conducted in Australia $(n=10)$. Thematic analysis of the eligible articles ( $n=41)$ revealed four themes: (I) increased app use related to shifts in parenting trends; (II) types of apps available to parents; (III) apps to overcome the digital divide; and (IV) factors encouraging or discouraging app use. Although numerous literature reviews have been conducted to explore parents' use of online resources, none of the reviews specifically focus on mobile apps developed to support parents in the first year of parenthood. This research advocates that health professionals and researchers should find alternatives to standardized means of delivering and developing parenting social support to fulfill contemporary parents' needs.
\end{abstract}

Keywords: Mobile applications (apps); parenting apps; mHealth; digital health; narrative review of the literature

Received: 27 September 2020; Accepted: 01 June 2021; Published: 30 November 2021.

doi: $10.21037 / \mathrm{ht}-20-28$

View this article at: http://dx.doi.org/10.21037/ht-20-28

\section{Introduction}

The birth of a first child can be an overwhelming and stressful experience for many parents due to adaptation to the new role, infant care responsibilities, and changes in spousal and social relationships. Social support refers to the provision of resources that helps an individual deal with stressful situations. The common forms of social support are informational and emotional support. Informational support is defined as the provision of advice, guidance, suggestions, or other useful information, in response to someone's needs $(1,2)$. Emotional support refers to the offering of empathy, compassion, and genuine concern to support individuals' emotional needs such as connecting with someone, talking about stressors and concerns, and seeking reassurance $(1,3)$. A combination of informational and emotional support improves parents' wellbeing and assists with their parenting concerns (1-3).

Mobile applications (apps) have the potential to provide informational and emotional support to parents 
24 hours a day, 7 days a week. Parents have consistently used apps to connect to other parents and professionals such as nurses, pediatricians, breastfeeding experts, and sleep training consultants. Parents use app features such as social networking, online forums, live chat, texts, and video calls to seek informational and emotional support on parenting matters $(4,5)$. Apps provide an anonymous venue to discuss and seek advice on sensitive issues, such as the resumption of sexual activities after childbirth, which some parents might not be comfortable sharing in person with family and friends. The anonymity allows parents to share their experiences, feelings, concerns, and intimate details regarding their childbirth experience more liberally without feeling judged (6).

Researchers around the world have introduced several apps to support parents in the first year of an infant's life $(7,8)$, however, parents continue to face difficulty finding apps that are credible and meet their expectations of usability and functionality. As a result, parents use non-secure and non-credible apps mostly developed by commercial entities that may lead to harmful parenting practices (9-11). There is a need to better understand parents' app use preferences and factors that encourage or discourage their apps' use. Therefore, the purpose of this narrative review of the literature is to provide a comprehensive overview of the multidisciplinary research on parents' use of apps in the first year of parenthood and highlight significant areas of research. This review aims to address the following research questions:

(I) What are the characteristics of literature on parents' app use in the first year of parenthood?

(II) What types of apps are available to parents to support their parenting in the first year?

(III) What are the factors that encourage or discourage parents' app use?

\section{Methodology}

The study combines a narrative review method and thematic analysis of the eligible articles to capture the novelty of the topic, as well as the breadth and diversity of the available research. This technique is suitable when addressing a broad area of research and the purpose is to describe the literature to expand the understanding of the topic $(12,13)$. The thematic analysis enables researchers to identify patterns and to describe various facets of the data (14).

\section{Search strategy}

Academic databases were searched for articles related to the topic using prespecified eligibility criteria. Articles were screened based on a reading of the abstracts. In cases where an abstract was not available, articles were scanned briefly and if relevant to the review topic, an analysis of the full text was conducted. The literature lacks research articles on the use of parenting apps among healthy parents of healthy infants. Therefore, in an effort to present a comprehensive review of the literature, conference presentations, master's/ doctoral theses, and relevant documents such as reports and viewpoints were also included in the search.

The following search terms were combined with the Boolean search operators AND, OR and NO: "Mobile Application" OR App OR Smartphone OR mHealth AND Parent OR Parenting OR Parenthood OR Parental OR Mother OR Mom OR Mum OR Motherhood OR Maternal OR Father OR Dad OR Daddy OR Fatherhood OR Paternal OR Infant OR Child OR Baby NOT Pregnancy OR Toddler OR Preschool OR Adolescent. The search from multiple disciplines such as nursing, medicine, psychology, and sociology was conducted using the following academic databases: CINAHL Plus with Full Text, MEDLINE, SocINDEX with Full Text, PsychINFO, Academic Search Complete, Web of Science, and Google Scholar.

\section{Eligibility criteria}

\section{Inclusion criteria}

Articles were included if they were full-text English language articles between January 2000 and December 2019 relating to parents' use of apps in the first year of infants' lives including reviews of parenting apps and apps that were developed to support parents.

\section{Exclusion criteria}

Articles were excluded if they were: duplicates $(n=50)$; published in a language other than English $(n=7)$; exclusively for children or parents of children above the age of 1 year $(n=110)$; targeting sick/preterm infants or their parents $(n=83)$; exclusively for pregnant parents $(n=13)$; targeting apps for health professionals or used by health professionals and researchers to collect data $(n=38)$, and not relevant to the topic $(n=455)$. A total 


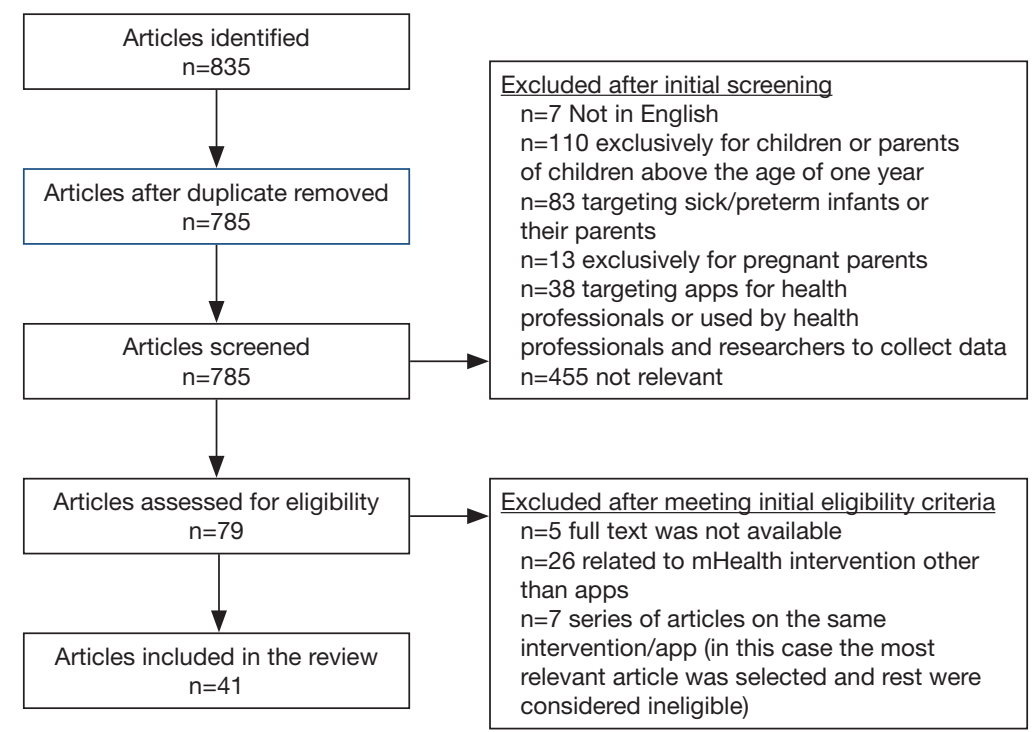

Figure 1 Article selection flowchart.

of 79 articles met the initial eligibility criteria and were reviewed by the primary author. Articles were further excluded if the full text was not available $(n=5)$; were related to mHealth intervention other than apps $(n=26)$, and series of articles on the same intervention/ app $(n=7)$ (in this case the most relevant article was selected and rest were considered ineligible). See Figure 1 for the article selection flowchart.

\section{Results}

\section{Characteristics of included studies}

Of the 835 articles identified in the initial search, a total of 41 met the eligibility criteria and included published research papers $(n=29)$, conference presentations $(n=5)$, unpublished master's thesis $(\mathrm{n}=2)$, and documents such as viewpoint articles and reports $(\mathrm{n}=5)$. A majority of the articles were related to an app or mHealth intervention that accompanied an app $(n=30)$, including a focus on informational and emotional support needs around infant care $(n=25)$, self-care $(n=4)$, and couple relationships $(n=1)$. The remaining 11 articles described parents' use of apps $(\mathrm{n}=5)$ and parenting app reviews/critiques $(\mathrm{n}=6)$. See Table 1 for the studies included in this literature review.

The majority of studies targeted women (including pregnant women and mothers) exclusively $(n=13)$ or in combination with health professionals $(n=2)$. Very few studies focused exclusively on male participants $(n=2)$ or in combination with health professionals $(n=1)$. Some researchers studied couples and families or parents of children under the age of 5 years $(n=5)$ while a few studied parents and health professionals $(n=2)$, as well as app development team members and app users $(n=1)$. Most studies were conducted in Australia $(n=10)$, followed by the United States of America ( $\mathrm{n}=5)$ and the United Kingdom $(\mathrm{n}=3)$ and one each in Canada, Denmark, Jordon, Uganda, Thailand, China, and Taiwan. In the remaining $(n=16)$ articles country was not mentioned.

Articles varied in their nature as some articles focused on social support needs about parenting, whereas others described the app development, deployment, and dissemination processes. Similarly, a wide variety of theoretical models were used $(n=10)$, of which only social cognitive theory (15) was mentioned twice. Other theories included: unified theory of acceptance and use of technology (16); technology acceptance model for mobile service (17); behavior change wheel (18); capability, opportunity, and motivation model of behavior change (18); theory of planned behavior (19); fun theory (20); theory of change (21); national extension relationship and marriage education model (22); family life course development theory (23); black feminist theory (24); analyzing children's creative thinking framework (25); taxonomy of play (26); and health belief model (27). 


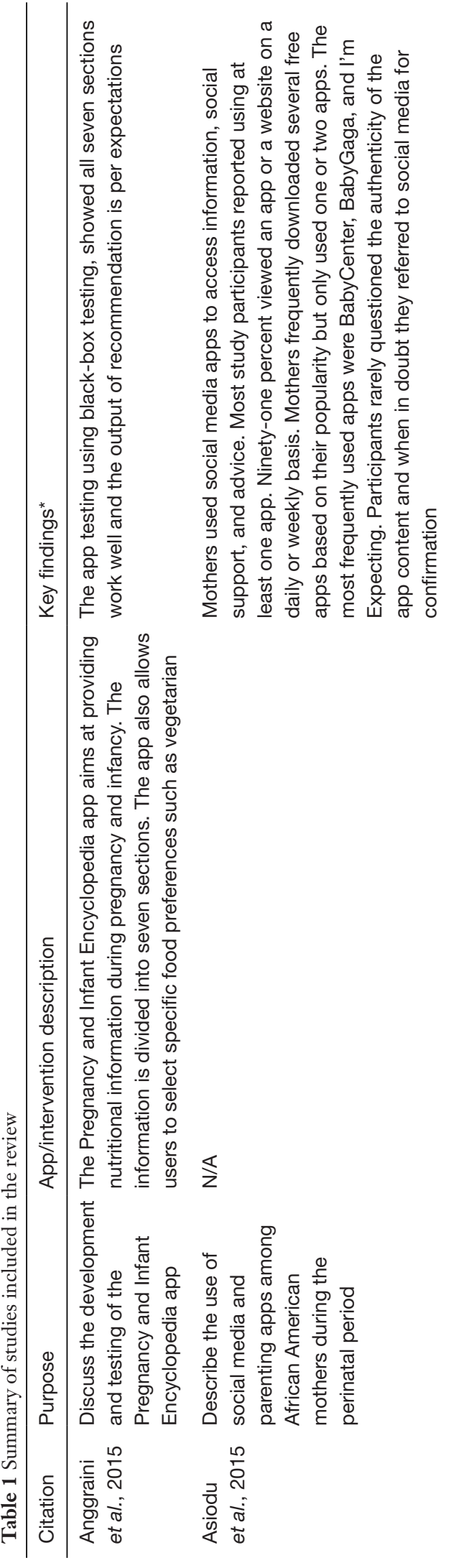

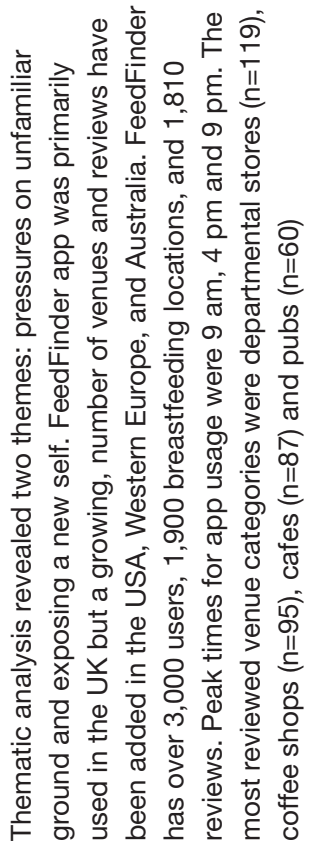
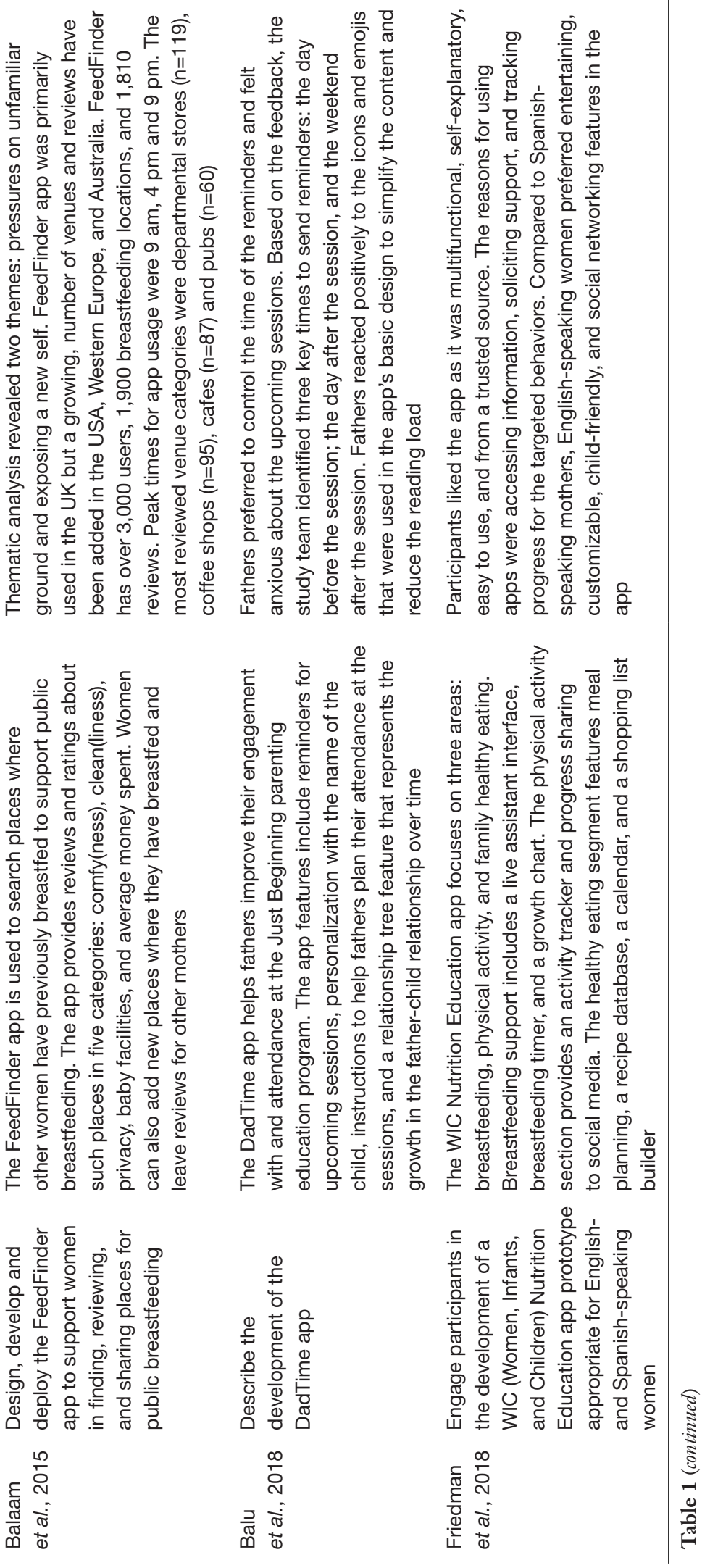


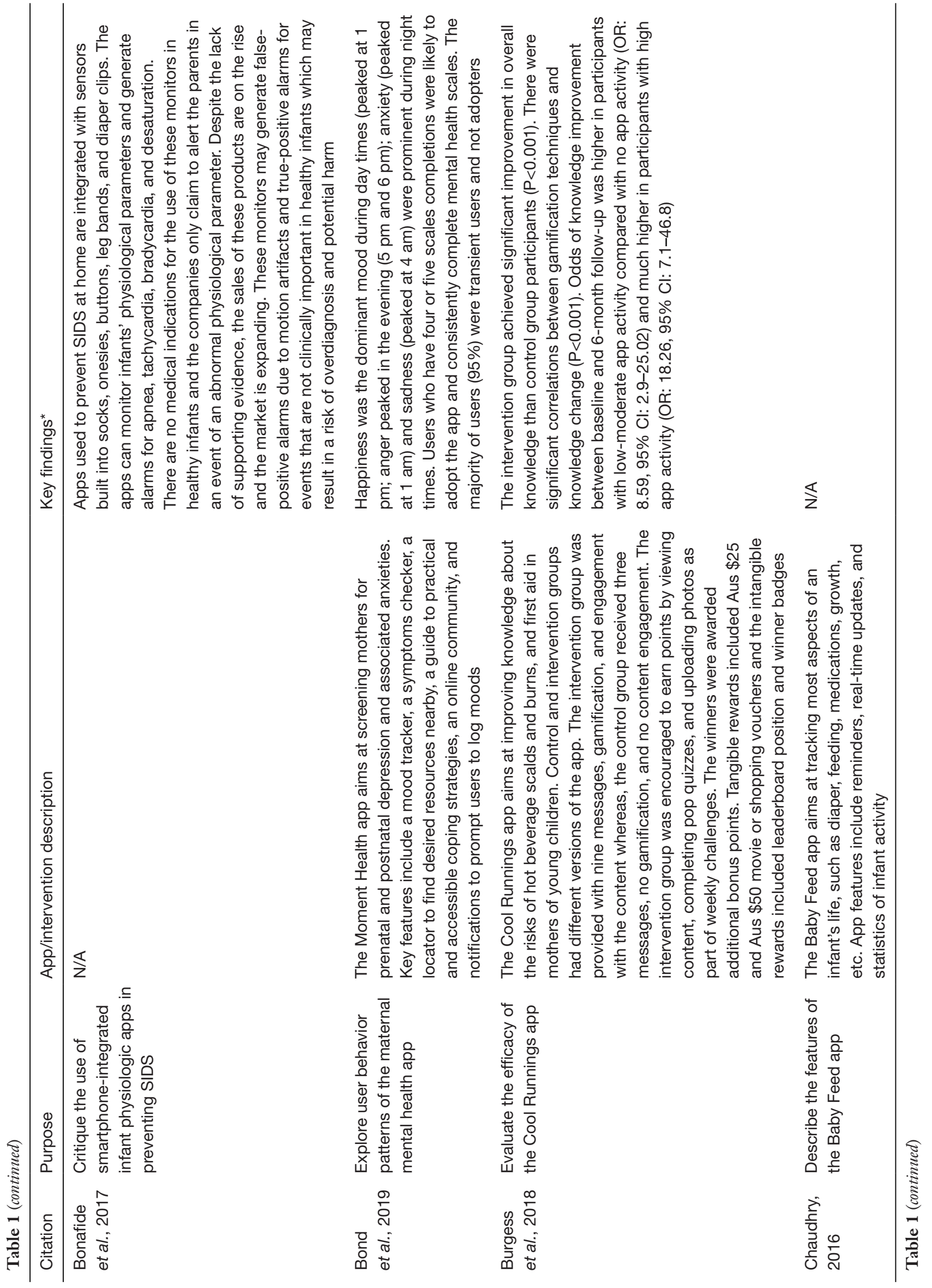




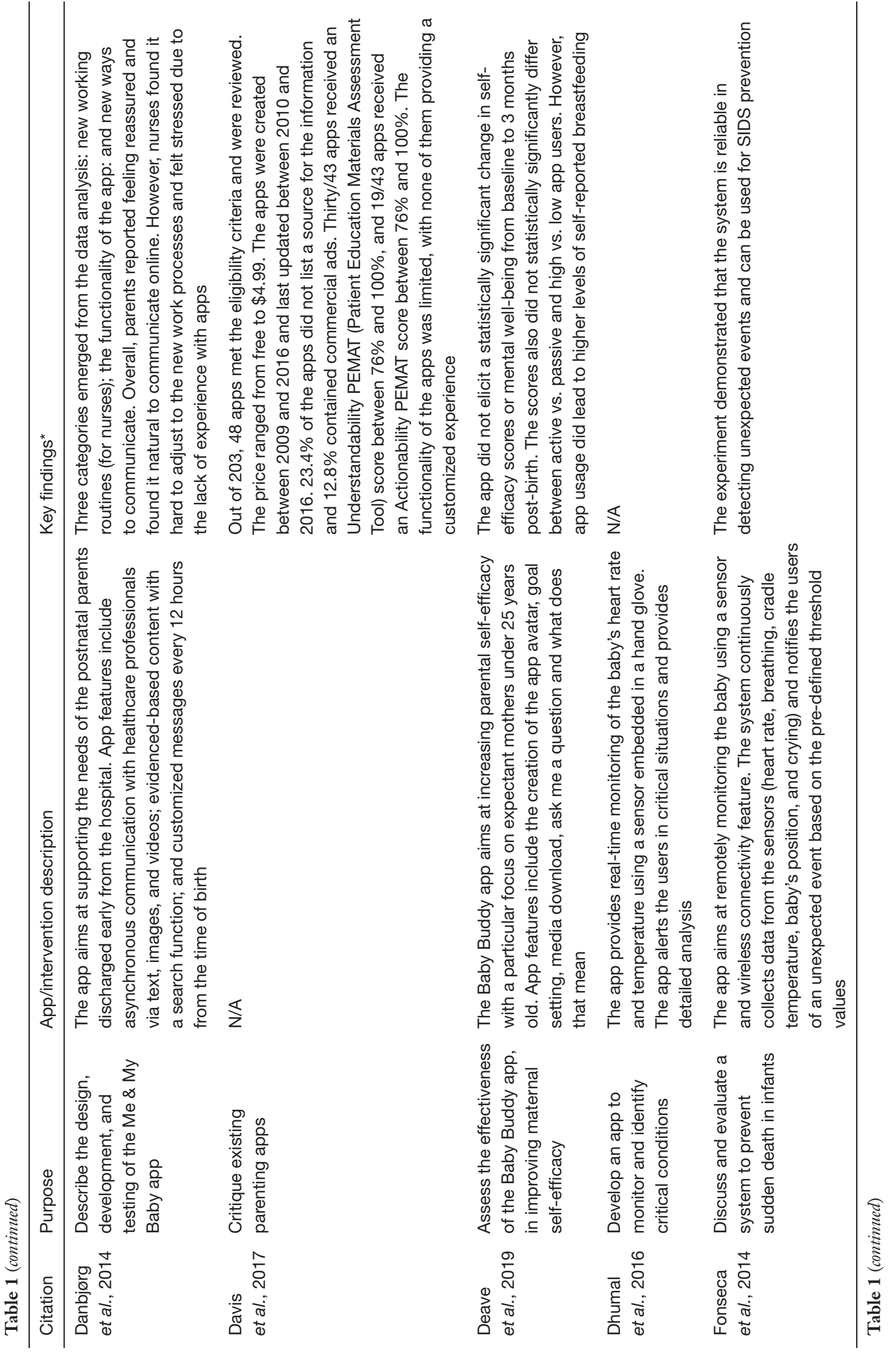



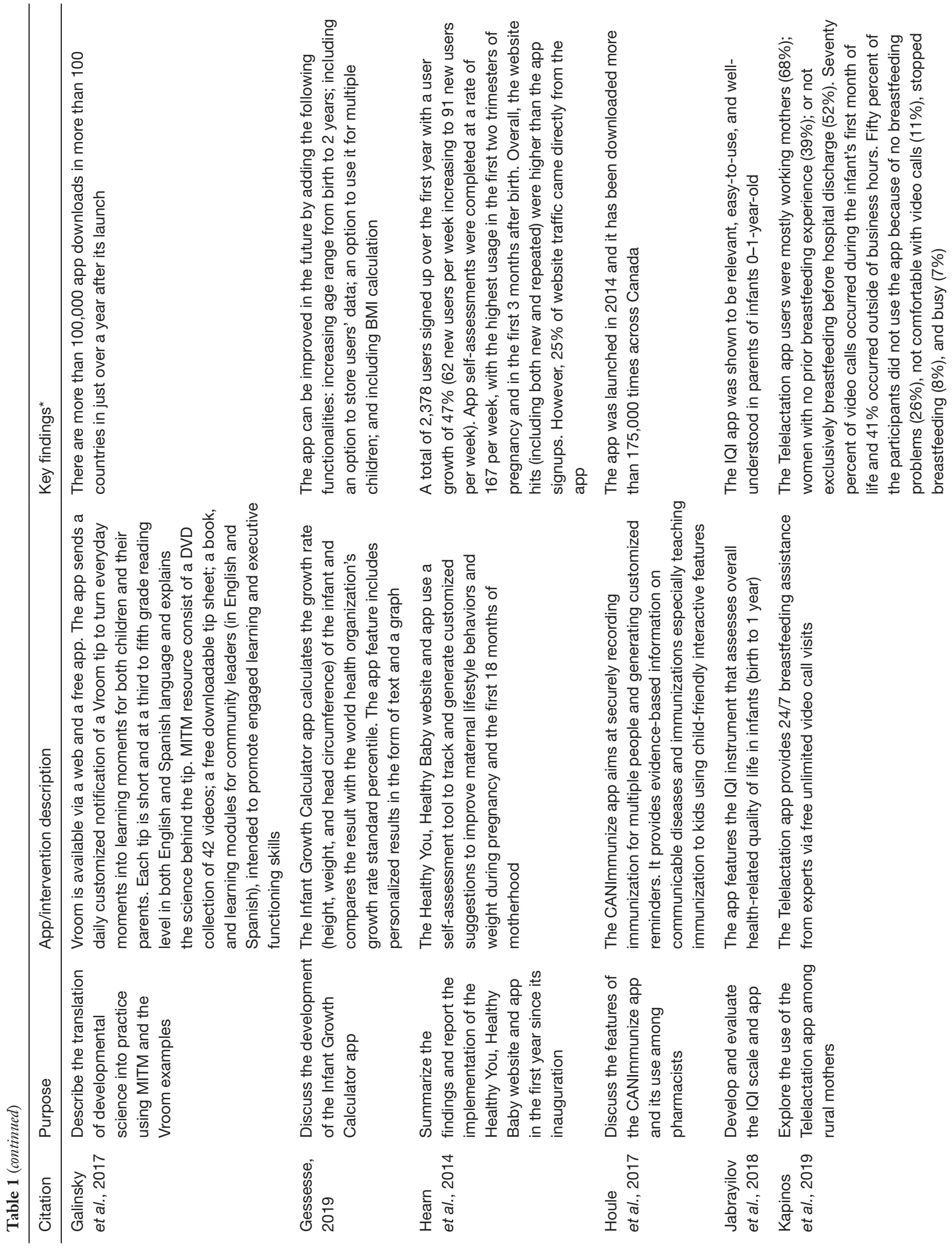


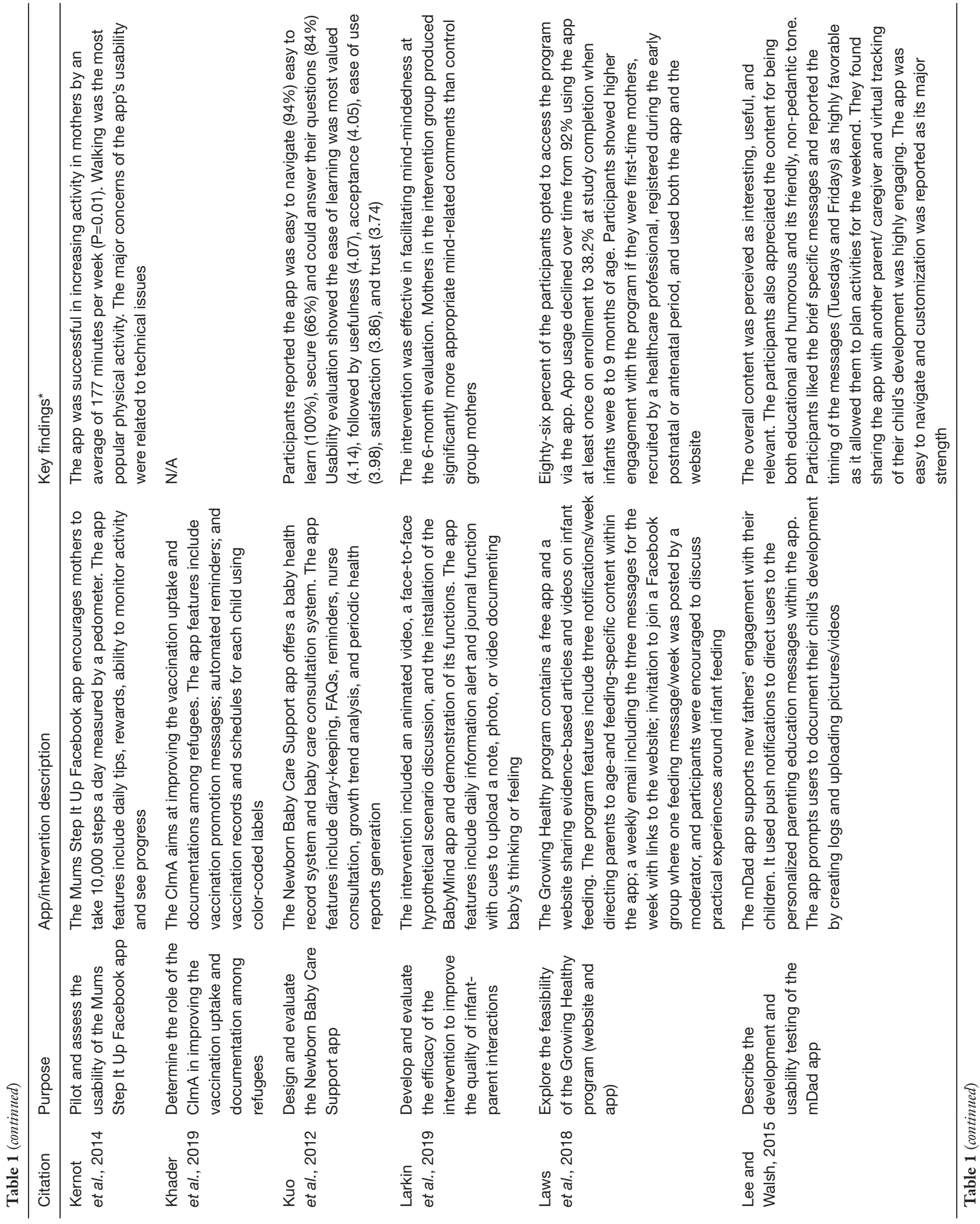




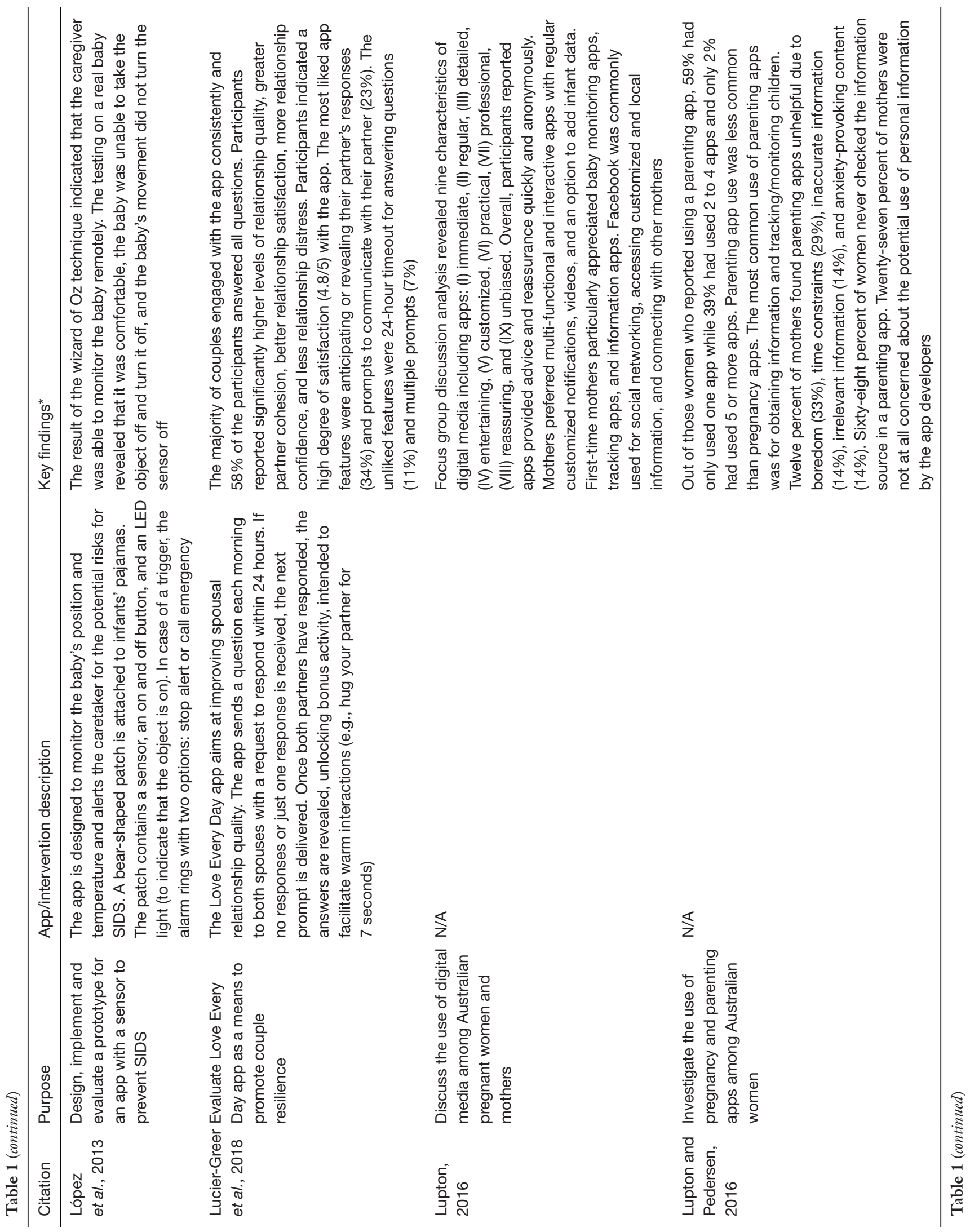



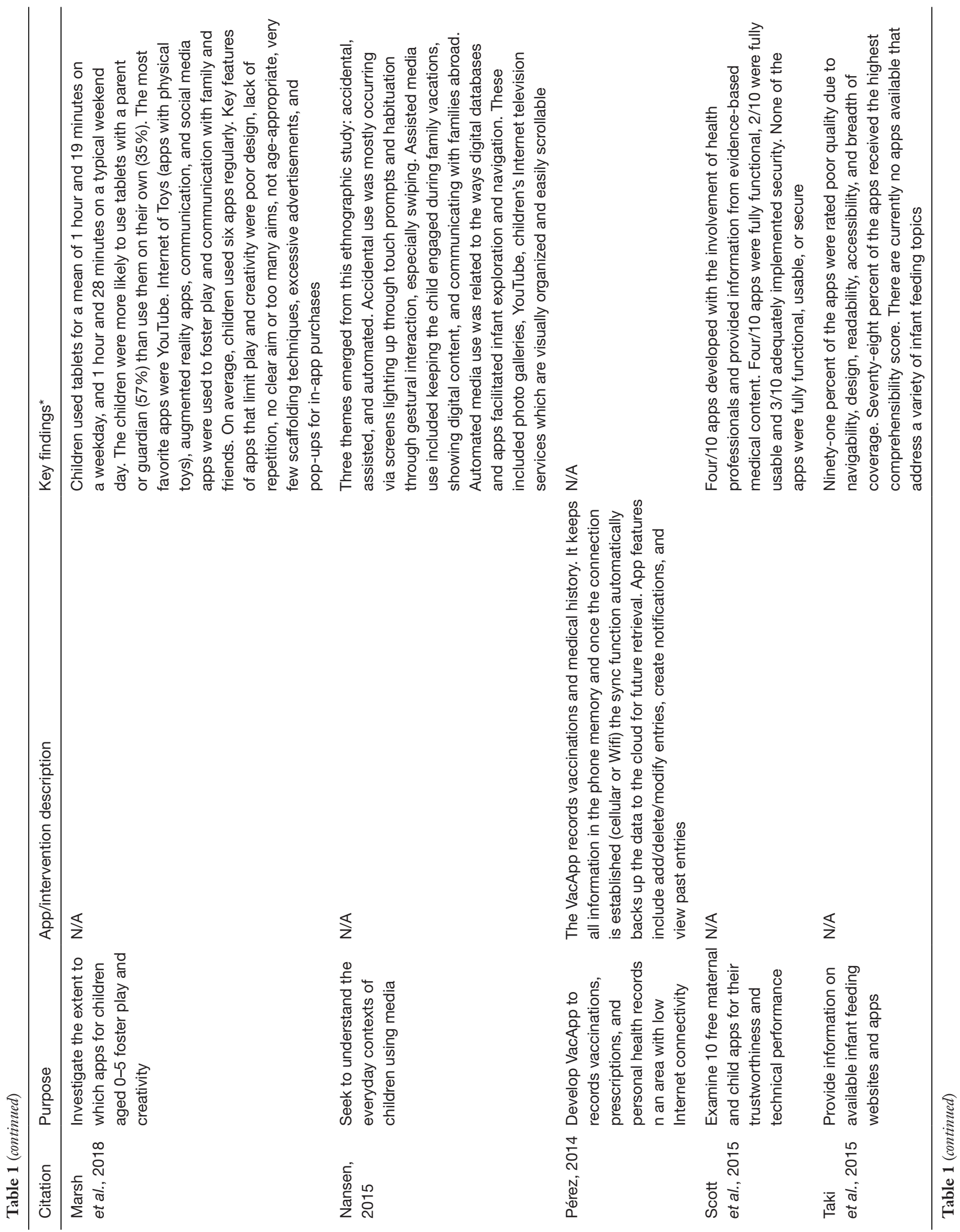


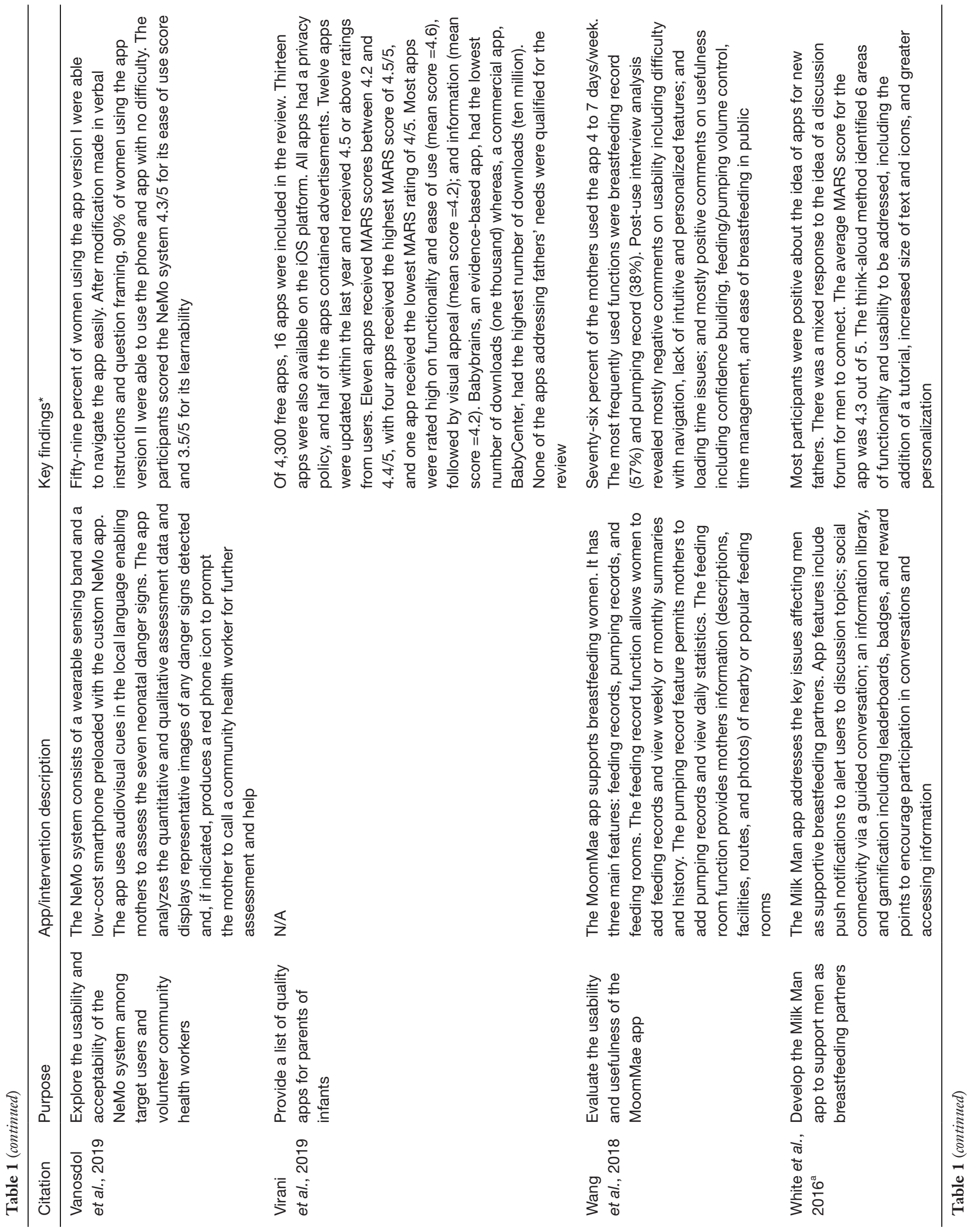




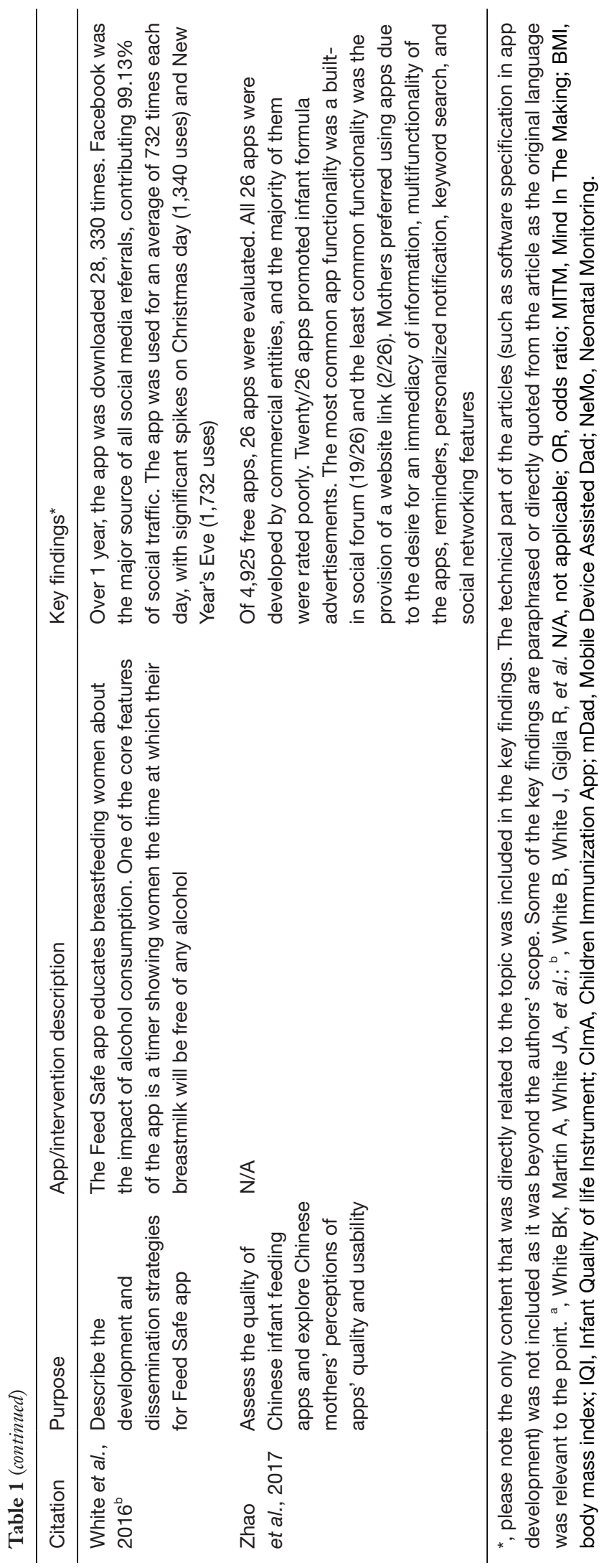




\section{Thematic analysis of the eligible articles}

The analysis revealed four overarching themes and 10 subthemes: (I) increased app use related to shifts in parenting trends; (II) types of apps available to parents; (III) apps to overcome the digital divide, and; (IV) factors encouraging or discouraging app use.

\section{Theme \#1. Increased app use related to shifts in parenting trends}

The literature review findings revealed that the inability of the healthcare system to support parents; evolving parenting roles due to increased participation of women in higher education and paid work; geographical distances between parents and their families; and the ubiquitous availability of scientific parenting material have greatly increased parents' app use. Three subthemes emerged: (I) shorter postnatal hospital stays; (II) evolving parenting roles and responsibilities; and (III) increased geographical distance among families and the rise of scientific parenting.

\section{Subtheme 1.1: shorter postnatal hospital stays}

Circumstances have changed over the last two decades contributing to the rise of app use among parents. Parents turn to apps in a quest for finding answers for common parenting needs due to healthcare system changes that restrict postpartum hospital stays. Many first-time parents are not mentally ready to absorb all the information presented to them in the brief period immediately after giving birth and commonly leave the hospital with numerous questions about their self-care and the needs of their newborn (28-30). In a study, postpartum parents reported feeling most vulnerable in the middle of the night when they could not contact family, friends, or clinicians (31). While support services such as parenting helplines, public health nurses' visits, and community centers are available in most communities, many parents reported reluctance to contact clinicians post-discharge due to concerns they were interrupting nurses' busy schedules to address their simple questions (32). On the other hand, apps act as a convenient medium for parents to fulfill their informational, and emotional support needs around-the-clock. Researchers in Denmark designed an app in collaboration with postpartum nurses in an effort to address the issue of shorter hospital stays and found the app to be an efficient source of parenting information. The findings revealed that parents preferred the app over typical sources, such as pamphlets and consulting nurses via phone (31).
Subtheme 1.2: evolving parenting roles and responsibilities In western societies, women are increasingly participating in higher education and paid employment. Stay-at-home fathers and dual-income families are increasing, giving rise to fathers' involvement in care and practical distribution of household responsibilities between working spouses. However, healthcare systems that are typically designed to support stay-at-home mothers often make fathers feel left out of the parenting process $(33,34)$. Fathers and working parents often turn to apps for information due to the inability of the healthcare system to adequately support the changing trends and shifts in parental responsibilities. While apps such as mDad, DadTime, and Milk Man assist fathers in their parenting roles (34-36), tracking apps allow working parents to remotely monitor their infants' care synchronously with caregivers $(33,37,38)$.

\section{Subtheme 1.3: increased geographical distance among families and the rise of scientific parenting}

Increased mobilization among parents to avail better career opportunities has led to an increase in geographical disconnection between new parents and their extended family support systems. Thus, parents are increasingly using communication and social media apps to connect with extended families and receive emotional and informational support $(39,40)$. Further, increased availability and awareness of scientific information have given rise to scientific parenting, defined as parenting practices that are based on best evidence (41). Zhao et al. (42) reported mothers are veering away from simply providing physical care to their infants and turning to apps that scientifically support their child-rearing practices and decision-making in health-related matters.

\section{Theme \#2. Types of apps available to parents}

Parents actively seek apps to adjust to their new role and there are several types of apps available to parents that can assist in meeting their social support needs. These needs can be categorized under the following two subthemes: (I) apps supporting infant care, and (II) apps focusing on selfcare and couple relationships.

\section{Subtheme 2.1: apps supporting infant care}

First-time parents, in particular, have numerous concerns about the overall well-being of their infants. The following infant care needs have received researchers/app developers' attention: overall infant care; feeding/nutrition; growth and vaccination tracking; and sudden infant death syndrome (SIDS) prevention. 
Parents desired apps that provided informational support to fulfill basic infant care needs, such as bathing an infant and care for the umbilical cord, in the initial postpartum months. For example, the app Newborn Baby Care Support was created to allow parents to consult nurses 24/7 during the postpartum period (29). Similarly, Danbjørg and colleagues (31) developed the app called Me \& My Baby that allowed parents to consult nurses via text, images, and videos and provided customized messages every 12 hours from the time of birth. Apps that provided support in dealing with other infant care such as infant cognitive and psychosocial development and parent-infant bonding were also valued by parents. Examples of such apps found were: mDad (34); DadTime (35); Vroom (43); and BabyMind (44).

Providing a healthy diet is an important aspect of infant care, and parents often report questions about breast/bottle feeding, the introduction of solids, and food allergies. Of all nutritional concerns reported by parents, by far breastfeeding received the most attention from researchers $(30,45,46)$, possibly due to declining rates of breastfeeding (36). The most common issues related to breastfeeding mentioned in the literature were sore/cracked nipples and latching problems, as well as lack of support from partners/family and breastfeeding in public. A few apps were created to deal with common breastfeeding concerns. The Telelactation app delivers new parents 24/7 breastfeeding assistance from lactation consultants via video chat (47) while the MoomMae app provides feeding/ pumping tracking and information on feeding rooms in public places (48). Recognizing the supportive role of a spouse in breastfeeding, White et al. (36) developed the cleverly titled Milk Man app that encourages fathers to act as a support for their breastfeeding partners. A few apps were developed to support parents' choices regarding healthy nutritious foods for infants such as the WIC Nutrition Education app (46), the Pregnancy and Infant Encyclopedia app (49), and the Growing Healthy app (50).

Tracking infants' basic activities, growth, and vaccinations were another reason parents use apps. The literature review revealed a few apps that assist parents in tracking infant development and vaccines. The Baby Feed app, for example, allows parents to record and track infants' basic activities such as feeding, urination/defecation, growth, and medications (37). The Infant Growth Calculator app enables parents to calculate the growth rate (height, weight, and head circumference) of infants and compares results with the World Health Organization growth rate standard percentiles (51). Using the CANImmunize app, parents can record immunizations for multiple family members and generate customized reminders for their next vaccination appointments (52).

SIDS prevention is another common concern of parents, and the focus of three articles found in this literature review $(33,38,53)$. Apps that come with a sensing device (attachable to the infant's clothing or surroundings) assist parents in detecting abnormal infants' physiological parameters and take action in time. However, Bonafide et al. (54), presented a critique of SIDS prevention apps and indicated that there is no evidence these apps are useful in preventing SIDS; rather, these apps appear to create a sense of insecurity among parents, heightening fears that they are incapable to keep their infants safe.

\section{Subtheme 2.2: apps focusing on self-care and couple relationships}

Personal care and relational activities enhance parents' feelings of well-being and social support $(1,3,6)$. Many parents seek informational support regarding self-care and couple relationships such as postpartum diet and exercise, resumption of sexual activities, and suggestions for maintaining a healthy spousal relationship. However, the literature review findings indicated that parents' self-care and spousal relationship needs received very little attention in the research $(\mathrm{n}=5)$ compared to infant care needs $(\mathrm{n}=25)$. Apps that were developed to support self-care included a social network-based physical activity app (20); a maternal mental health app (28); a maternal lifestyle and weight management app (55); and an app to increase maternal selfefficacy (56). Only one app, Love Every Day (57), was found to promote couple resilience.

\section{Theme \#3. Apps developed to overcome the digital divide}

The term digital divide is commonly used to denote barriers in online information access. Inequalities based on age, income, education, availability of devices, and the Internet, as well as comfort level and skills required to use technology, prevent some people from using the Internet and apps, creating a divide between technology and nontechnology users (58). Despite the prevalence of some degree of the digital divide, however, contemporary parents are increasingly using apps to fulfill their informational and emotional support needs $(55,59)$. Given the increase in online health information, several health professionals and researchers have designed apps to improve access to health 
services and information for parents who are difficult to reach through typical methods (pamphlets, consultations, and classes) due to geographical barriers, time constraints, and stigma $(31,32,57)$. This literature review found several apps that were specifically developed for disadvantaged or vulnerable populations such as military and low-income fathers (34); mothers living in rural and remote areas (47); high-risk mothers (56); parents with low socioeconomic status $(43,50,60,61)$; refugees $(62)$; and areas of low internet connectivity (63).

\section{Theme \#4. Factors encouraging or discouraging parenting app use}

The abundance of poor-quality parenting apps was mentioned as a major barrier in the effective utilization of apps. Serval researchers have performed parenting app reviews and mentioned most apps were of poor quality (64-66). For example, Virani et al. (67), reported out of 4,300 parenting apps reviewed, only $16(0.4 \%)$ were relevant and of high quality. The majority of app reviews have suggested five areas to improve app quality to make them more appealing to parents, categorized under the following five subthemes: (I) functionality, (II) visual appeal, (III) interactive feature, (IV) content credibility, and (V) privacy and security $(40,59,68)$.

\section{Subtheme 4.1: functionality}

Functionality refers to app performance, ease of use, and navigation. Apps that are difficult to navigate, freeze, or crash can frustrate users. Many users delete dysfunctional apps within a few minutes after installation due to navigation issues. The seamless functioning of apps is very important in utilization $(20,46,50)$.

\section{Subtheme 4.2: visual appeal}

Often referred to as look and feel, visual appeal is an important aesthetic aspect that allows users to enjoy their experience. The app icon and logo provide the first impression of an app that communicates its quality even before users decide to download and test its functionality $(66,67)$.

\section{Subtheme 4.3: interactive feature}

Interactive features of an app are crucial in engaging parents, improving control, and ensuring effortless ongoing access to desired parenting social support. Interactive features such as trackers $(52,63)$, reminders $(37,62)$, notifications $(33,43)$, connecting with clinicians via video calling or texting $(31,47)$, gamification $(36,60)$, using geolocation to find nearby places for breastfeeding $(45,48)$, and forums/social networking $(20,42)$ were mentioned in the literature to create appealing evidence-based apps for parents.

\section{Subtheme 4.4: content credibility}

Credible content in an app is critical from researchers' and healthcare professionals' perspectives however, the analysis suggested otherwise. If an app is usable, engaging, and customizable, parents are willing to compromise on content credibility. Many evidence-based apps are content robust but lack appealing and usable features that discourage the use of such apps among parents. For example, Scott et al. (64) presented a parenting app review and found four apps with evidence-based content, out of which two did not fully meet the usability criteria. A few researchers shared concerns that lack of usable and appealing features such as seamless navigation, ease of use, and interactive features deter parents from using evidence-based apps thus put them at a risk of using content that may lead to harmful practices $(32,42,67)$.

\section{Subtheme 4.5: privacy and security}

App security mechanisms allow users to enjoy apps safely. However, many parenting apps, especially ones that provide customized information, collect and store personalized data on a daily basis. Users usually have no means and/or are unaware of the methods of deleting collected data and many apps do not use encrypted data sending features, making data prone to hacking $(33,37)$. Scott et al. (64) examined ten free maternal and child apps and found only three apps employed a security mechanism to ensure users' security. While evidence-based apps take extra caution in ensuring users' security $(29,52)$, researchers have found that parents continued to use commercial and/or poor-quality apps if they helped fulfill social support needs despite potential privacy and security issues $(55,66,69)$.

\section{Discussion}

Through this literature review, the authors aim to explore characteristics of literature on parents' app use in the first year of parenthood, types of apps that provide informational and emotional support in the first year, and the factors that support and hinder parents' app use.

The findings indicated the majority of apps provided social support for infant care and only a handful of apps discussed self-care and couple relationships. Gilmer et al. (70), found similar results in a review of the literature on parenting education interventions. They indicated the majority of interventions focused on parenting an infant. However, the importance of self-care and couple 
relationships cannot be denied in maintaining overall parental wellbeing. Hearn et al. (55) performed a gap analysis for parenting content and reported mothers felt the available parenting content was "child-focused" and they would prefer to have "parent-focused" content (p.3). Entsieh and Hallström (71) presented a literature review on the parental needs of first-time parents in early parenthood which also indicated that managing the spousal relationship was one of the important needs identified by parents.

Self-care and spousal relationships are some of the needs that were identified in this literature review that is lacking in the world of parenting apps and require researchers and app developers' attention. Many researchers who evaluated parenting programs also supported the similar notion that a lot of emphases was given on learning about labor, delivery, and infant care, and little attention was given to parents' emotional health, self-confidence, couple's relationships, and parenting skills $(55,70,71)$. There is a need to shift the focus from developing apps to support infant care to apps that enhance parent's self-confidence, support their mental health, educate them about coping strategies, dealing with new challenges and budling resilience, help them learn parenting skills, facilitate self-care activities, and provide support in maintaining healthy family, and social relationships. In these tough times, when parents are feeling more isolated and experiencing mental health challenges due to the pandemic related social distancing measures, the need to develop apps that supports parents beyond infant care cannot be stressed enough.

Findings revealed that most researchers employed mothers as participants and a few involved fathers in research. Evolving circumstances have given rise to father's involvement and fathers are more involved in the child rearing activities than ever before. Further, the involvement of fathers in infant care has proven to be beneficial in the well-being of mothers and infants. Fathers also play an important role in a child's physical, mental and social development (34-36). Inclusion of fathers' perception in designing parenting resources is crucial therefore, researchers should also recruit fathers in parenting related research studies (72). A few researchers have also discussed the challenges of recruiting fathers such as work-related responsibilities and uncomfortableness with parenting programs which are mostly geared towards mothers $(11,35,73)$. However, Lee and Walsh (34) suggested researchers should try different recruitment strategies and recruit even a small sample of fathers in research to make them feel heard and to develop parenting resources that are more accessible and appealing to them.

The review findings suggest parents prefer appealing, usable, functional, and personalized apps with interactive features and for that experience, many parents do not hesitate to compromise on content credibility and security features. There could be many possible reasons for such findings. First, some researchers found many evidencebased apps are content robust and secure but lack parents' preferred features. Second, many evidence-based apps go through a stringent process of research and modifications before they are available to the public. Some evidence-based apps are only designed for one platform such as iOS or android which further limits their availability and visibility. For example, Virani et al. (67), found that while a literature search revealed a few evidence-based apps for fathers, these apps were not available on the Google app store. Third, evidence-based apps are low in number compared to poor quality apps which makes the process of finding a usable, appealing, secure, and credible app similar to finding a needle in a haystack $(64,74,75)$. There is a need to develop credible and secure apps that are also usable and appealing to parents and available to the public on multiple platforms. A partnership between academia and the technology industry may result in such apps (76). Using user inclusive approaches such as participatory design to engage parents in the app development process can also result in apps that are not only are scientifically robust and secure but also appealing to parents.

\section{Implication for practice}

Parents often have busy schedules and generally select social support sources that require less time and are easily accessible. Danbjørg et al. (31) found parents preferred a postnatal app where they could send a picture, video, or text compared to consulting nurses over the phone. Considering shifting trends in accessing parenting social support, health professionals and researchers should recommend quality apps to parents $(39,65,69)$. Deave et al. (56) reported parents were more likely to use an app if it was introduced or recommended by a health professional. Most parenting app reviews, however, presented quality issues with apps but did not guide health professionals or parents towards quality apps. Virani et al. (67) stressed the importance of providing 
a list of quality apps that may ease the search process for parents and increase recommendations of apps by health professionals.

It is alarming to note that parents compromise on content credibility and security features due to the immediacy of the fulfillment of their needs and certain app features that make the app more usable or visually appealing. Parents tend to discard high-quality apps with evidence-based information due to poor visual appeal and lack of usable features (11). While evidence-based apps pay more attention to content credibility and security, they may lack appealing features that deter parents from utilizing these apps. Therefore, it is important to co-create apps with parents and incorporate their suggestions in app development. Vanosdol et al. (61) modified the NeMo app by incorporating users' feedback and indicated modification increased mothers' ability to accurately spot neonatal danger signs by at least $200 \%$. Researchers should engage parents in the app development process to create appealing and usable evidence-based apps. The use of user inclusive approaches to design, such as participatory design, can be employed to engage users in the app development process.

\section{Limitations}

Narrative reviews are generally less systematic due to the flexibility of including different types of research and nonresearch articles; however, this flexibility allows researchers to incorporate a wide variety of literature and provide a comprehensive overview of the topic. Further, the authors did not perform a quality assessment of the included articles due to the heterogenicity of the theoretical perspectives and reported methods and results.

\section{Conclusions}

In this narrative review of the literature, the authors have discussed the types of apps available to parents providing informational and emotional support; evolving circumstances that have given rise to parents' app use; and app features that encourage or discourage parents' use of quality apps. Contemporary parents' increased use of apps demands health professionals to move from standardized approaches to providing parenting social support and adopting digital mediums to increase parents' access to evidence-based resources. Parenting app reviewers should focus on providing a list of quality apps that health professionals can recommend to parents. Researchers should employ methods to co-create apps with parents to increase the uptake of evidence-based apps among parents.

\section{Acknowledgments}

The authors would like to thank Dr. Eleni Stroulia, Professor, Faculty of Science, University of Alberta, for her participation in the conception and design of the project as one of the supervisory committee members.

Funding: None.

\section{Footnote}

Peer Review File: Available at http://dx.doi.org/10.21037/ ht-20-28

Conflicts of Interest: All authors have completed the ICMJE uniform disclosure form (available at http://dx.doi. org/10.21037/ht-20-28). The authors have no conflicts of interest to declare.

Ethical Statement: The authors are accountable for all aspects of the work in ensuring that questions related to the accuracy or integrity of any part of the work are appropriately investigated and resolved.

Open Access Statement: This is an Open Access article distributed in accordance with the Creative Commons Attribution-NonCommercial-NoDerivs 4.0 International License (CC BY-NC-ND 4.0), which permits the noncommercial replication and distribution of the article with the strict proviso that no changes or edits are made and the original work is properly cited (including links to both the formal publication through the relevant DOI and the license). See: https://creativecommons.org/licenses/by-nc-nd/4.0/.

\section{References}

1. Letourneau N, Secco L, Colpitts J, et al. Quasiexperimental evaluation of a telephone-based peer support intervention for maternal depression. J Adv Nurs 2015;71:1587-99.

2. Stewart M. Chronic conditions and caregiving in Canada: social support strategies. Toronto: University of Toronto Press, 2000.

3. DeHoff BA, Staten LK, Rodgers RC, et al. The role of online social support in supporting and educating parents of young children with special health care needs in the 
United States: a scoping review. J Med Internet Res 2016;18:e333.

4. Lupton D, Pedersen S, Thomas G. Parenting and digital media: From the early web to contemporary digital society. Sociol Compass 2016;10:730-43.

5. Duggan M, Lenhart A, Lampe C, et al. Parents and social media. Pew Research Center. 2015. Available online: https://www.pewresearch.org/internet/2015/07/16/ parents-and-social-media/

6. Johnson SA. 'Intimate mothering publics': comparing face-to-face support groups and Internet use for women seeking information and advice in the transition to firsttime motherhood. Cult Health Sex 2015;17:237-51.

7. Franciscovich A, Vaidya D, Doyle J, et al. PoopMD, a mobile health application, accurately identifies infant acholic stools. PLoS One 2015;10:e0132270.

8. Morse SS, Murugiah MK, Soh YC, et al. Mobile health applications for pediatric care: review and comparison. Ther Innov Regul Sci 2018;52:383-91.

9. Colliver Y, Hatzigianni M, Davies B. Why can't I find quality apps for my child? A model to understand all stakeholders' perspectives on quality learning through digital play. Early Child Dev Care 2020;190:2612-26.

10. Richardson B, Dol J, Rutledge K, et al. Evaluation of mobile apps targeted to parents of infants in the neonatal intensive care unit: systematic app review. JMIR Mhealth Uhealth 2019;7:e11620.

11. Virani A, Duffett-Leger L, Letourneau N. Parents' perspectives of parenting app use. J Inform Nurs 2020;5:8-18.

12. Mays N, Pope C, Popay J. Systematically reviewing qualitative and quantitative evidence to inform management and policy-making in the health field. J Health Serv Res Policy 2005;10 Suppl 1:6-20.

13. Snyder H, Engström J. The antecedents, forms and consequences of patient involvement: a narrative review of the literature. Int J Nurs Stud 2016;53:351-78.

14. Clarke V, Braun V. Thematic analysis. In: Michalos AC. editor. Encyclopaedia of quality of life and well-being research. Dordrecht: Springer, 2014:6626-8.

15. Bandura A. Social foundations of thought and action: a social cognitive theory. Hoboken: Prentice-Hall, Inc., 1986.

16. Venkatesh V, Morris M, Davis GB, et al. User acceptance of information technology: Toward a unified view. MIS Q 2003;27:425-78.

17. Kaasinen E. User acceptance of mobile services. In: Lumsden J. editor. Handbook of research on user interface design and evaluation for mobile technology. London: IGI
Global, 2008:102-21.

18. Michie S, van Stralen MM, West R. The behaviour change wheel: a new method for characterising and designing behaviour change interventions. Implement Sci 2011;6:42.

19. Ajzen I. From intentions to actions: A theory of planned behavior. In: Kuhl J, Beckmann J. editors. Action control. Heidelberg: Springer, 1985:11-39.

20. Kernot J, Olds T, Lewis LK, et al. Usability testing and piloting of the Mums Step It Up program--a team-based social networking physical activity intervention for women with young children. PLoS One 2014;9:e108842.

21. De Silva MJ, Breuer E, Lee L, et al. Theory of Change: a theory-driven approach to enhance the Medical Research Council's framework for complex interventions. Trials 2014;15:267.

22. Futris TG, Adler-Baeder F. The national extension relationship and marriage education model: Core teaching concepts for relationship and marriage enrichment programming. Georgia: University of Georgia Press, 2013. Available online: https://www.fcs.uga.edu/docs/ NERMEM.pdf

23. Bengtson VL, Allen KR. The life course perspective applied to families over time. In: Boss P, Doherty WJ, LaRossa R, et al. editors. Sourcebook of family theories and methods. Boston: Springer, 2009:469-504.

24. Collins PH. Black feminist thought: Knowledge, consciousness, and the politics of Empowerment. New York: Routledge, 2008.

25. Robson S. The Analysing Children's Creative Thinking Framework: Development of an observation-led approach to identifying and analysing young children's creative thinking. Br Educ Res J 2014;40:121-34.

26. Hughes B. A playworker's taxonomy of play types. 2nd ed. London: PlayLink, 2002.

27. Rosenstock IM. Why people use health services. Milbank Mem Fund Q 1966;44:Suppl:94-127.

28. Bond R, Moorhead A, Mulvenna M, et al. Exploring temporal behaviour of app users completing ecological momentary assessments using mental health scales and mood logs. Behav Inform Technol 2019;38:1016-27.

29. Kuo MC, Lu YC, Chang P. A newborn baby care support app and system for mHealth. NI 2012 (2012) 2012;2012:228.

30. White BK, Giglia RC, Scott JA, et al. How new and expecting fathers engage with an app-based online forum: qualitative analysis. JMIR Mhealth Uhealth 2018;6:e144.

31. Danbjørg DB, Wagner L, Clemensen J. Designing, developing, and testing an app for parents being discharged 
early postnatally. J Nurse Pract 2014;10:794-802.

32. Asiodu IV, Waters CM, Dailey DE, et al. Breastfeeding and use of social media among first-time African American mothers. J Obstet Gynecol Neonatal Nurs 2015;44:268-78.

33. Dhumal S, Kumbhar N, Tak A, et al. Wearable health monitoring system for babies. IJCET 2016;7:15-23.

34. Lee SJ, Walsh TB. Using technology in social work practice: the mDad (mobile device assisted dad) case study. Advances in Social Work 2015;16:107-24.

35. Balu R, Lee S, Steimle S. Encouraging attendance and engagement in parenting programs: developing a smartphone application with fathers, for fathers. 2018 (Accessed 2019 December 29). Available online: https://deepblue.lib.umich.edu/bitstream/ handle/2027.42/149449/2018_Balu_b3_dadtime_ brief_508.pdf?sequence $=1 \&$ isAllowed $=y$

36. White BK, Martin A, White JA, et al. Theory-based design and development of a socially connected, gamified mobile app for men about breastfeeding (Milk Man). JMIR Mhealth Uhealth 2016;4:e81.

37. Chaudhry BM. Baby statistics: there is an App for that! Mhealth 2016;2:23.

38. Fonseca AM, Horta ET, Sendra S, et al. A sudden infant death prevention system for babies. In: Proceedings of the IEEE 16th International Conference on e-Health Networking, Applications and Services (Healthcom). Brazil, 2014:525-30.

39. Marsh J, Plowman L, Yamada-Rice D, et al. Play and creativity in young children's use of apps. Br J Educ Technol 2018;49:870-82.

40. Nansen B. Accidental, assisted, automated: An emerging repertoire of infant mobile media techniques. M/C Journal 2015. Available online: https://journal.media-culture.org. au/index.php/mcjournal/article/view/1026

41. Letourneau N, Joschko J. Scientific parenting: What sciences reveals about parental influence. Toronto: Dundurn, 2013.

42. Zhao J, Freeman B, Li M. How do infant feeding apps in China measure up? A Content Quality Assessment. JMIR Mhealth Uhealth 2017;5:e186.

43. Galinsky E, Bezos J, McClelland M, et al. Civic science for public use: mind in the making and vroom. Child Dev 2017;88:1409-18.

44. Larkin F, Oostenbroek J, Lee Y, et al. Proof of concept of a smartphone app to support delivery of an intervention to facilitate mothers' mind-mindedness. PLoS One 2019;14:e0220948.
45. Balaam M, Comber R, Jenkins E, et al. FeedFinder: A location-mapping mobile application for breastfeeding women. In: Proceedings of the CHI. Seoul, 2015.

46. Friedman LB, Silva M, Smith K. A focus group study observing maternal intention to use a WIC education app. Am J Health Behav 2018;42:110-23.

47. Kapinos K, Kotzias V, Bogen D, et al. The use of and experiences with telelactation among rural breastfeeding mothers: secondary analysis of a randomized controlled trial. J Med Internet Res 2019;21:e13967.

48. Wang CJ, Chaovalit P, Pongnumkul S. A breastfeedpromoting mobile app intervention: usability and usefulness study. JMIR Mhealth Uhealth 2018;6:e27.

49. Anggraini RN, Soedjono AR, Sianipar FY. Infant and pregnancy encyclopedia application. In: Proceedings of the International Conference on Advanced Mechatronics, Intelligent Manufacture, and Industrial Automation 2015 (ICAMIMIA 2015). Indonesia, 2015. Available online: https://www.researchgate.net/ profile/Ratih_Anggraini/publication/307800387_ Infant_and_pregnancy_encyclopedia_application/ links/5d401e9b4585153e592d3196/Infant-and-pregnancyencyclopedia-application.pdf

50. Laws RA, Denney-Wilson EA, Taki S, et al. Key Lessons and Impact of the Growing Healthy mHealth Program on Milk Feeding, Timing of Introduction of Solids, and Infant Growth: Quasi-Experimental Study. JMIR Mhealth Uhealth 2018;6:e78.

51. Gessesse Y. Infant growth calculator: Android mobile application. Vaasa: Vaasan Ammattikorkeakoulu (WAMK) University of Applied Sciences, 2019. Available online: https:/www.theseus.fi/bitstream/handle/10024/170878/ Gessesse_Yemeskabeba.pdf?sequence $=2$

52. Houle SKD, Atkinson K, Paradis M, et al. CANImmunize: A digital tool to help patients manage their immunizations. Can Pharm J (Ott) 2017;150:236-8.

53. López G, López M, Guerrero LA. An augmented object prototype for helping to prevent the sudden infant death syndrome. In: International Workshop on Ambient Assisted Living. Cham: Springer, 2013:132-5.

54. Bonafide CP, Jamison DT, Foglia EE. The emerging market of smartphone-integrated infant physiologic monitors. JAMA 2017;317:353-4.

55. Hearn L, Miller M, Lester L. Reaching perinatal women online: the Healthy You, Healthy Baby website and app. J Obes 2014;2014:573928.

56. Deave T, Ginja S, Goodenough T, et al. The Bumps and BaBies Longitudinal Study (BaBBLeS): a multi-site cohort 
study of first-time mothers to evaluate the effectiveness of the Baby Buddy app. Mhealth 2019;5:42.

57. Lucier-Greer M, Birney AJ, Gutierrez TM, et al. Enhancing Relationship Skills and Couple Functioning with Mobile Technology: An Evaluation of the Love Every Day Mobile Intervention. J Fam Soc Work 2018;21:152-71.

58. Dworkin J, Connell J, Doty J. A literature review of parents' online behavior. Cyberpsychol Behav Soc Netwfrt 2013. doi: 10.5817/CP2013-2-2.

59. Lupton D. The use and value of digital media for information about pregnancy and early motherhood: a focus group study. BMC Pregnancy Childbirth 2016;16:171.

60. Burgess J, Watt K, Kimble RM, et al. Combining Technology and Research to Prevent Scald Injuries (the Cool Runnings Intervention): Randomized Controlled Trial. J Med Internet Res 2018;20:e10361.

61. Vanosdoll M, Ng N, Ho A, et al. A Novel Mobile Health Tool for Home-Based Identification of Neonatal Illness in Uganda: Formative Usability Study. JMIR Mhealth Uhealth 2019;7:e14540.

62. Khader YS, Laflamme L, Schmid D, et al. Children Immunization App (CImA) Among Syrian Refugees in Zaatari Camp, Jordan: Protocol for a Cluster Randomized Controlled Pilot Trial Intervention Study. JMIR Res Protoc 2019;8:e13557.

63. Pérez RG. VacApp: Mobile tool for the child vaccination control. Barcelona: Polytechnic University of Catalonia (UPC), 2014. Available online: https://upcommons.upc. edu/handle/2099.1/24277

64. Scott KM, Gome GA, Richards,D, et al. How trustworthy are apps for maternal and child health? Health and Technology 2015;4:329-36.

65. Davis DW, Logsdon MC, Vogt K, et al. Parent education is changing: a review of smartphone apps. MCN Am J

doi: $10.21037 /$ ht-20-28

Cite this article as: Virani A, Duffett-Leger L, Letourneau N. Parents' use of mobile applications in the first year of parenthood: a narrative review of the literature. Health Technol 202 1;5:14.
Matern Child Nurs 2017;42:248-56.

66. Taki S, Campbell KJ, Russell CG, et al. Infant Feeding Websites and Apps: A Systematic Assessment of Quality and Content. Interact J Med Res 2015;4:e18.

67. Virani A, Duffett-Leger L, Letourneau N. Parenting apps review: in search of good quality apps. Mhealth 2019;5:44.

68. Jabrayilov R, van Asselt ADI, Vermeulen KM, et al. A descriptive system for the Infant health-related Quality of life Instrument (IQI): Measuring health with a mobile app. PLoS One 2018;13:e0203276.

69. Lupton D, Pedersen S. An Australian survey of women's use of pregnancy and parenting apps. Women Birth 2016;29:368-75.

70. Gilmer C, Buchan JL, Letourneau N, et al. Parent education interventions designed to support the transition to parenthood: a realist review. Int J Nurs Stud 2016;59:118-33.

71. Entsieh AA, Hallström IK. First-time parents' prenatal needs for early parenthood preparation-A systematic review and meta-synthesis of qualitative literature. Midwifery 2016;39:1-11.

72. Shorey S, Dennis CL, Bridge S, et al. First-time fathers' postnatal experiences and support needs: a descriptive qualitative study. J Adv Nurs 2017;73:2987-96.

73. Kane N. Stay-at-home fatherhoods. Contexts 2015;14:74-6.

74. Hingle M, Patrick H. There are thousands of apps for that: navigating mobile technology for nutrition education and behavior. J Nutr Educ Behav 2016;48:213-8.e1.

75. Jake-Schoffman DE, Silfee VJ, Waring ME, et al. Methods for evaluating the content, usability, and efficacy of commercial mobile health apps. JMIR Mhealth Uhealth 2017;5:e190.

76. White B, White J, Giglia R, et al. Feed Safe: a multidisciplinary partnership approach results in a successful mobile application for breastfeeding mothers. Health Promot J Austr 2016;27:111-7. 